\title{
Characterizing environmental risk factors for West Nile virus in Quebec, Canada, using clinical data in humans and serology in pet dogs
}

\author{
J. P. ROCHELEAU ${ }^{1 *}$, P. MICHEL ${ }^{1,2}$, L. R. LINDSAY ${ }^{3}$, M. DREBOT $^{3}$, \\ A. DIBERNARDO ${ }^{3}$, N. H. OGDEN ${ }^{1,4}$, A. FORTIN ${ }^{5}$ AND J. ARSENAULT ${ }^{1,6}$ \\ ${ }^{1}$ Groupe de recherche en épidémiologie des zoonoses et santé publique, Faculté de médecine vétérinaire, Université \\ de Montréal, Saint-Hyacinthe, Québec, Canada \\ ${ }^{2}$ Office of the Chief Science Officer, Public Health Agency of Canada, Ottawa, Ontario, Canada \\ ${ }^{3}$ National Microbiology Laboratory, Public Health Agency of Canada, Winnipeg, Manitoba, Canada \\ ${ }^{4}$ National Microbiology Laboratory, Public Health Agency of Canada, Saint-Hyacinthe, Québec, Canada \\ ${ }^{5}$ Institut national de santé publique, Québec, Québec, Canada \\ ${ }^{6}$ Département de pathologie et microbiologie vétérinaire, Faculté de médecine vétérinaire, Université de Montréal, \\ Saint-Hyacinthe, Québec, Canada
}

Received 21 April 2017; Final revision 20 June 2017; Accepted 11 July 2017;

first published online 24 August 2017

\section{SUMMARY}

The identification of specific environments sustaining emerging arbovirus amplification and transmission to humans is a key component of public health intervention planning. This study aimed at identifying environmental factors associated with West Nile virus (WNV) infections in southern Quebec, Canada, by modelling and jointly interpreting aggregated clinical data in humans and serological data in pet dogs. Environmental risk factors were estimated in humans by negative binomial regression based on a dataset of 191 human WNV clinical cases reported in the study area between 2011 and 2014. Risk factors for infection in dogs were evaluated by logistic and negative binomial models based on a dataset including WNV serological results from 1442 dogs sampled from the same geographical area in 2013. Forested lands were identified as low-risk environments in humans. Agricultural lands represented higher risk environments for dogs. Environments identified as impacting risk in the current study were somewhat different from those identified in other studies conducted in north-eastern USA, which reported higher risk in suburban environments. In the context of the current study, combining human and animal data allowed a more comprehensive and possibly a more accurate view of environmental WNV risk factors to be obtained than by studying aggregated human data alone.

Key words: Dogs, environmental risk factors, public health, West Nile virus.

\section{INTRODUCTION}

West Nile virus (WNV) is an arthropod-borne flavivirus with possible clinical impact on various vertebrate

\footnotetext{
* Author for correspondence: J.-P. Rocheleau, Groupe de recherche en épidémiologie des zoonoses et santé publique, Faculté de médecine vétérinaire, Université de Montréal, 3200 rue Sicotte, Saint-Hyacinthe, QC, Canada, J2S 2M2.

(Email: jean-philippe.rocheleau@umontreal.ca)
}

hosts [1]. It is currently the leading cause of arboviral neuroinvasive diseases in humans in the USA and Canada [2]. In the USA, more than 18000 clinical cases of WNV disease were reported between 1999 and 2014 [3]. WNV was first introduced into the province of Quebec, Canada, in 2002 [4]. Since then, an increase in WNV activity has occurred in the southern part of the province, which has led to increased public health efforts including surveillance [4]. 
WNV is maintained in nature through complex transmission cycles involving a variety of mosquito vectors and avian amplifying hosts. The risk of transmission in a given region mainly depends on the abundance of competent vectors, on the abundance of amplifying hosts, on the vector-host contact rates and on climate. These four components of the WNV transmission cycle are known to be associated with local and regional environmental conditions [1,5-8]. The identification of key environmental risk factors influencing risk of WNV transmission is an important step for public health prevention, allowing targeting of interventions, such as enhanced surveillance, preventive mosquito control, and information campaigns to where they are the most needed $[9,10]$. However, the complexity of WNV epidemiology and its dependence on local factors lead to variations in the risk factors influencing transmission, and therefore the high-risk environments identified in different geographical locations across North America may differ [11-17].

Estimates of WNV seroprevalence in dog populations range from $4 \%$ to $37 \%$ in different parts of the world [18-23]. A number of authors have suggested that dogs could act as sentinels for WNV surveillance $[18,19,23]$. Moreover, a study comparing WNV seroprevalence rates in dogs and humans in southern Quebec reported that seroprevalence in adult pet dogs was more than five times higher than seroprevalence in humans from the same region, giving the opportunity to monitor or study WNV spillover in the dog population [24]. According to this study, regional seroprevalence would be highly correlated between humans and dogs, suggesting that environmental factors associated with infection would be similar in both species.

The current study aimed to identify environmental factors associated with WNV infection in southern Quebec by modelling and jointly interpreting aggregated clinical data in humans and serological data in dogs. The potential benefits of using a multispecies approach for characterising WNV public health risk are discussed.

\section{MATERIALS AND METHODS}

A cross-sectional study was conducted to quantitatively estimate the association between environmental or demographical factors and WNV infections in humans and dogs living within the same geographical area of southern Quebec, Canada, from 2011 to 2014. The administrative regions of Montreal, Laval and Montérégie and the southern parts of Lanaudière and Laurentides were selected to conduct the analysis (Fig. 1a). The northern parts of Lanaudière and Laurentides were excluded from the study area as they are mainly uninhabited forested areas from which no human WNV clinical cases have ever been reported. The city of Montreal and its suburbs, located in the centre of the study area, are surrounded by the flat and highly agricultural lowland areas of the SaintLawrence River Valley, themselves surrounded by rolling forested hills mainly covered by hardwood or mixed forest (Fig. 1b). The study area includes a total of 318 municipalities, which represented a population of approximately 4.7 million people in 2011 . These 318 municipalities were distributed among 35 counties.

\section{Datasets}

\section{Epidemiological data}

Two epidemiological datasets were used to conduct the statistical analysis. The first dataset included all human clinical cases reported to the Ministry of Health and Social Services of the province of Quebec from 2011 to 2014. Only the municipality of residence of each clinical case at the time of diagnosis was available in this dataset. Of the 214 cases reported in the province of Quebec from 2011 to 2014, 191 lived within the study area at the time of diagnosis. These 191 cases were distributed across 55 municipalities.

The second dataset comprised information on WNV seroprevalence in dogs from a broader multispecies serological arbovirus survey conducted in 2013 [24]. Briefly, blood samples were taken from dogs in veterinary clinics and hospitals distributed in the five selected regions during spring and summer 2013. Veterinary clinics and hospitals were selected randomly based on a provincial registry. Among the 213 veterinary clinics that had a sufficient dog-owning clientele to allow participation in the study, $89(42 \%)$ agreed to participate. Approximately 20 dogs were selected by convenience in each participating clinic or hospital. Antibodies against WNV in dogs were analyzed as described in Rocheleau [24]. Briefly, samples were first screened by competitive ELISA with a cut-off of 30\% inhibition for positivity, and all positive samples were confirmed by plaque reduction neutralization tests (PRNT). A sample was considered positive if its PRNT titre was determined to be $1: 20$ or greater. All laboratory tests were conducted at the National Microbiology Laboratory (Public Health Agency of Canada, Winnipeg, Manitoba). Diagnostic 

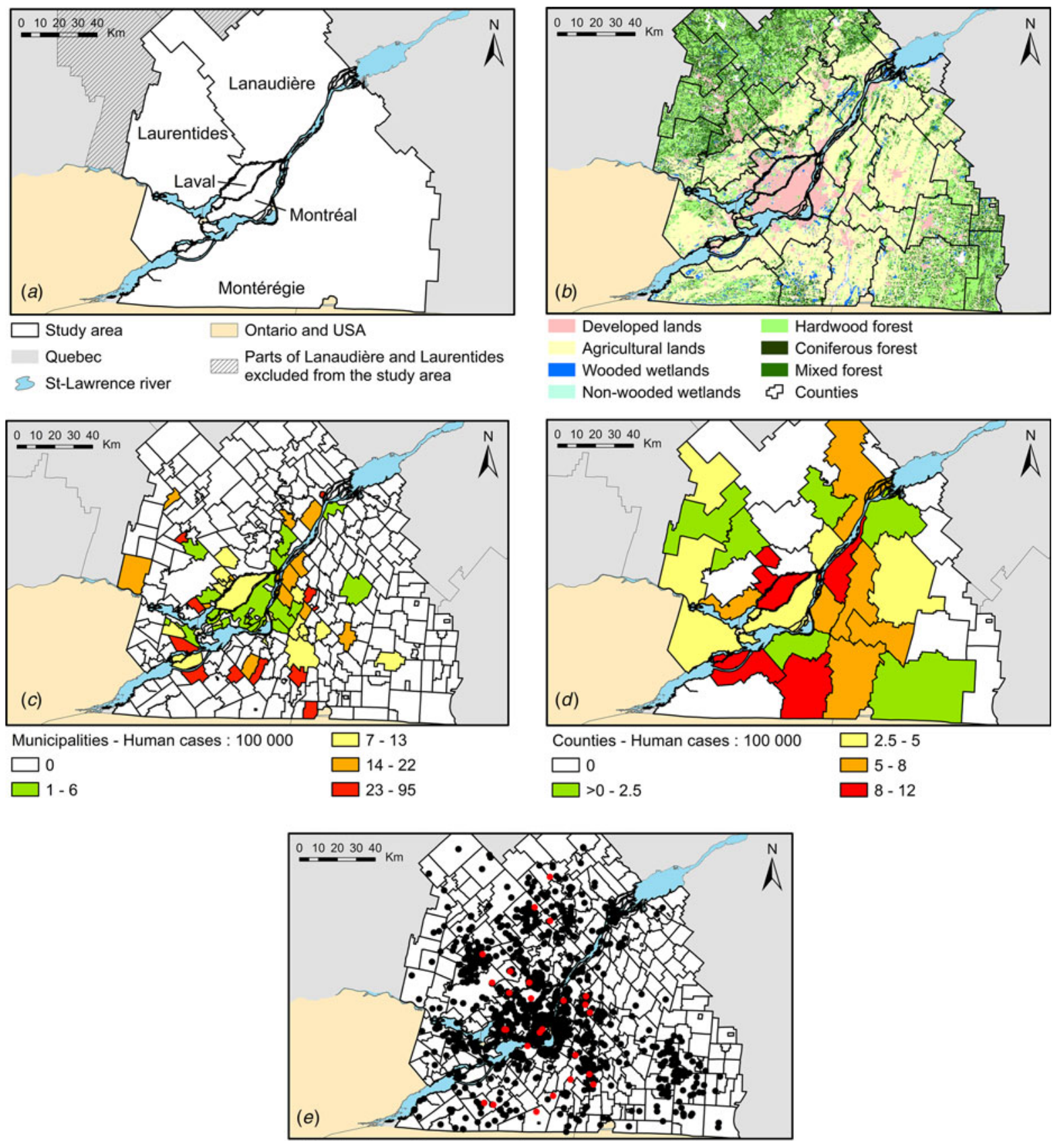

Point locations of households where dogs were sampled

- Seronegative dog

- Seropositive dog

[5 Municipalities

Fig. 1. Geographical representation of descriptive data. (a) Study area; (b) municipalities and land cover classification within the study area; $(c)$ incidence risk per 100000 people for the 2011-2014 period in municipalities included in the study area; $(d)$ incidence risk per 100000 people for the 2011-2014 period in counties included in the study area; $(e)$ geographical distribution and serological status of the $1627 \mathrm{dogs}$, 2013. Cut-off values for the classification of incidence risk in $(c)$ and $(d)$ were based on the quartiles of the incidence risk distribution. Source for administrative boundaries: Statistics Canada, 2011 Census boundary files, August 2013.

test results were obtained from 1627 dogs. The dog dataset included the address of the property where each of the dogs lived and information about age, time spent outside daily, date of sampling, breed, sex, hair length, use of insecticide, flea medication or mosquito repellent, presence and size of pools of 
standing water on the property, time since the dog was acquired by its current owner, time spent outside the municipality of residence during the mosquito season and travel history. Complete records were available for 1442 of the $1627(88.6 \%)$ dogs sampled. These 1442 dogs lived in 1419 households and were distributed across 207 municipalities. A subset of 883 dogs that had never left their municipality of residence during the mosquito season and that had never travelled outside of Canada were derived from the dataset of 1442 dogs. Dogs were categorized as 'adults' if they were born before 1 November 2012 and as 'juvenile' otherwise. These categories aimed at distinguishing exposure of dogs to mosquitoes before (adult dogs only) or during the 2013 summer season (the only season of exposure for juvenile dogs).

\section{Land cover data}

Land cover classification for the whole study area was retrieved from the Ecoforest Inventory System of the Ministry of Forests, Fauna and Parks, updated in 2013 (Ministère des Forêts, Faune et Parcs, MFFP). The percentage of area of each municipality and each county covered by each type of land cover (agricultural lands, developed lands, surface water, hardwood forest, mixed forest, coniferous forest, orchards, wooded and non-wooded wetlands, disturbed lands (vacant vegetated areas highly affected by human activity) or roads/highways) was calculated. For each dog included in the analysis, land cover data were calculated as the percentage of area covered by each of the aforementioned land cover inside circular areas of $2 \mathrm{~km}$ radius centred on the house. This radius was chosen according to the usual flying distances reported for various vectors possibly involved in WNV transmission [25-27]. All manipulations and calculations of geographic data were accomplished using ArcGIS 10.2.2 (ESRI, Redlands, California, USA).

\section{Human population data}

Total population for each municipality and county were retrieved from Statistics Canada's 2011 census.

\section{Analyses}

\section{Descriptive statistics}

In humans, incidence risk per 100000 for the 20112014 period was calculated for the whole study area and for each administrative region, county and municipality included in the study area, and mapped at the county and municipality level. The mean and median of the percentage of area covered by each land cover were calculated for municipalities, counties and for the circular areas surrounding sampled dog's houses. Descriptive statistics for the individual characteristics of sampled dogs were presented.

\section{Regression modelling of human case data}

Negative binomial (NB) regression was first used to model the risk of WNV clinical cases in humans according to environmental factors (see Table 1). Analyses were conducted on two geographical scales, one based on the municipality and the other based on the county as the epidemiological unit of interest. The outcome variables were the counts of human clinical cases in each municipality or county, with the log of the total human population within each municipality or county used as an offset. Correlations between risk factors on their original continuous scale were assessed by Pearson's correlation coefficient. If two risk factors were highly correlated $(r>0 \cdot 7)$, only one was kept, selected on the basis of greatest biological relevance. Univariate regression was conducted on remaining risk factors. The assumption of linearity was assessed by plotting a loess smooth curve against the standardized Pearson residuals of the models. When the relationship was deemed not to be linear, risk factors were categorized according to their quartile values [28]. When contrasts between some categories of a risk factor were not significantly different at $P<0 \cdot 05$, adjacent categories were merged. Environmental risk factors showing a statistically significant association at $P<0 \cdot 20$ (type III test) on univariate NB regression were included in a full multivariate model. A manual backward procedure was used to refine the model with a cut-off at $P>0.05$ for variable rejection, with the exception of potential confounders that were forced into the models. A risk factor was considered to be a confounder if its removal from the model induced a $>20 \%$ change in the estimated coefficient value of another predictor or if its potential confounding effect was expected based on biological criteria. Two-way interactions were tested between the final model's predictors if biologically relevant. NB models' fit was assessed by computing the ratio of the Deviance $\chi^{2}$ statistic on its degrees of freedom (Deviance/DF) [28]. A ratio over 1.25 or $<0.8$ was considered as being indicative of poor model fit. 
Table 1. Descriptive statistics for variables included in regression models for infection by WNV in humans and dogs from five administrative regions of southern Quebec

\begin{tabular}{|c|c|c|c|c|c|c|}
\hline \multirow[b]{2}{*}{ Population data } & \multicolumn{2}{|c|}{ Municipalities $(n=318)$} & \multicolumn{2}{|c|}{ Counties $(n=35)$} & \multicolumn{2}{|c|}{$\begin{array}{l}\text { House surroundings }{ }^{\mathrm{a}} \\
(n=1442)\end{array}$} \\
\hline & Mean & Median & Mean & Median & Mean & Median \\
\hline Population & 14985 & 2506 & 134867 & 55621 & - & - \\
\hline Land cover data & $(\%)$ & $(\%)$ & $(\%)$ & $(\%)$ & $(\%)$ & $(\%)$ \\
\hline Agricultural lands & $40 \cdot 6$ & $40 \cdot 8$ & $40 \cdot 0$ & $42 \cdot 7$ & $19 \cdot 4$ & $6 \cdot 6$ \\
\hline Developed lands & $17 \cdot 0$ & $4 \cdot 8$ & $13 \cdot 2$ & $6 \cdot 8$ & $38 \cdot 8$ & $3 \cdot 1$ \\
\hline Surface water & $2 \cdot 5$ & $0 \cdot 9$ & $1 \cdot 9$ & $1 \cdot 0$ & $6 \cdot 6$ & $1 \cdot 1$ \\
\hline Hardwood forest & $20 \cdot 1$ & $16 \cdot 0$ & $21 \cdot 2$ & $15 \cdot 8$ & $11 \cdot 4$ & $6 \cdot 2$ \\
\hline Mixed forest & $9 \cdot 7$ & $4 \cdot 3$ & $12 \cdot 0$ & $9 \cdot 4$ & $6 \cdot 4$ & $0 \cdot 1$ \\
\hline Coniferous forest & $2 \cdot 1$ & $1 \cdot 0$ & $2 \cdot 6$ & $2 \cdot 0$ & $1 \cdot 0$ & $0 \cdot 0$ \\
\hline Orchards & $0 \cdot 3$ & $0 \cdot 0$ & $0 \cdot 4$ & $0 \cdot 0$ & $0 \cdot 1$ & $0 \cdot 0$ \\
\hline Wooded wetlands & $2 \cdot 8$ & $1 \cdot 3$ & $3 \cdot 2$ & $2 \cdot 9$ & $1 \cdot 5$ & $0 \cdot 0$ \\
\hline Non-wooded wetlands & $1 \cdot 4$ & $0 \cdot 5$ & $1 \cdot 4$ & $1 \cdot 3$ & $0 \cdot 6$ & $0 \cdot 0$ \\
\hline Disturbed lands & $0 \cdot 7$ & $<0 \cdot 1$ & $0 \cdot 7$ & $0 \cdot 5$ & $0 \cdot 7$ & $0 \cdot 0$ \\
\hline Roads & $0 \cdot 5$ & 0 & $0 \cdot 4$ & $0 \cdot 3$ & $0 \cdot 4$ & $0 \cdot 0$ \\
\hline
\end{tabular}

${ }^{\text {a }}$ Circular areas of $2 \mathrm{~km}$ radius around the houses of sampled dogs.

\section{Regression modelling in dogs}

NB models were developed from the dog serology dataset using the same method as described for the models using human case data to allow for a comparison of risk factor estimates between species at an aggregated scale. The outcome variable was the number of seropositive dogs within each municipality or county, whereas the log of the total number of dogs sampled within each municipality or county was used as the offset.

Logistic regression models were thereafter used on the serology dataset in dogs to model the log odds of seropositivity according to individual and environmental risk factors at the individual level in dogs. These logistic models were used to account for the potential confounding effect of individual factors in dogs and to identify environmental factors on a smaller geographical scale than the one used in NB modelling. Hence, for logistic modelling in dogs, environmental risk factors were defined as the area covered by each land cover in the immediate surroundings of the house, namely within the $2 \mathrm{~km}$ radius circular areas described above. Logistic models were built following the steps described for NB models. The whole logistic model building procedure was conducted on two nested datasets, one including 1442 dogs for which complete questionnaire data were available, and one including only the 883 dogs which had never left their home municipality or Canada.
Logistic models fit and predictive ability were evaluated by the Hosmer and Lemeshow (HL) fit statistic and the area under the receiver operating characteristic curve (AUC).

\section{RESULTS}

The study area, the geographical distribution of land covers within the study area and the choropleth maps of municipalities and counties showing the incidence of human WNV clinical cases per 100000 people for the 2011-2014 period are presented in Figure $1 a-d$. The average annual incidence risk for reported WNV cases in humans for the 2011-2014 period was approximately 1 per 100000 in the whole study area. The regional incidence risk per 100000 for the entire 2011-2014 period was 8.2 for the region of Laval, $5 \cdot 2$ for Montérégie, $5 \cdot 0$ for southern Laurentides, 2.9 for Montreal and 1.3 for southern Lanaudière. The incidence risk within each municipality ranged from 0 to 95 per 100000 inhabitants for this 4 -year period, with no cases in $83 \%$ of the municipalities. The incidence risk within each county ranged from 0 to 12 per 100000 inhabitants for this 4 -year period, with no cases reported in $34 \%$ of the counties.

Descriptive statistics for the mean and median percentage of each land cover within the municipalities and counties of the study area and demographical statistics are presented in Table 1. 
Table 2. Univariate associations between environmental factors and risk of infection in humans or seropositivity in dogs based on negative binomial county-level models

\begin{tabular}{|c|c|c|c|c|c|c|c|}
\hline \multirow[b]{2}{*}{ Environmental factor } & \multirow[b]{2}{*}{$\begin{array}{l}\text { Categories } \\
(\% \text { of county area) }\end{array}$} & \multicolumn{3}{|l|}{ Humans } & \multicolumn{3}{|l|}{$\operatorname{Dogs}^{\mathrm{a}}$} \\
\hline & & $\begin{array}{l}\text { Incidence risk } \\
\text { in humans }{ }^{\mathrm{b}}\end{array}$ & $\beta$ & $P$-value & $\begin{array}{l}\% \text { seropositive } \\
\text { in } \operatorname{dogs}^{c}\end{array}$ & $\beta$ & $P$-value \\
\hline \multirow[t]{2}{*}{ Agricultural lands } & $<58 \cdot 5^{\mathrm{d}}$ & $3 \cdot 8$ & $\operatorname{Ref}^{e}$ & & $1 \cdot 4$ & Ref & \\
\hline & $\geqslant 58 \cdot 5$ & $6 \cdot 2$ & 0.53 & $0 \cdot 15$ & $2 \cdot 6$ & 0.62 & $0 \cdot 19$ \\
\hline \multirow[t]{2}{*}{ Developed lands } & $<6 \cdot 8$ & $2 \cdot 6$ & Ref & & 1.9 & Ref & \\
\hline & $\geqslant 6.8$ & $4 \cdot 2$ & $0 \cdot 61$ & $0 \cdot 11$ & $1 \cdot 5$ & $-0 \cdot 26$ & $0 \cdot 56$ \\
\hline \multirow[t]{2}{*}{ Surface water } & $<1 \cdot 0$ & $4 \cdot 3$ & Ref & & $1 \cdot 8$ & Ref & \\
\hline & $\geqslant 1 \cdot 0$ & $3 \cdot 4$ & $-0 \cdot 33$ & $0 \cdot 32$ & $1 \cdot 3$ & $-0 \cdot 35$ & $0 \cdot 41$ \\
\hline \multirow[t]{3}{*}{ Hardwood forest } & $<15 \cdot 8$ & $4 \cdot 5$ & Ref & & $1 \cdot 8$ & Ref & \\
\hline & $15 \cdot 8-30 \cdot 0$ & $2 \cdot 4$ & $-0 \cdot 81$ & 0.034 & $1 \cdot 5$ & $-0 \cdot 18$ & 0.72 \\
\hline & $\geqslant 30 \cdot 0$ & $1 \cdot 4$ & $-1 \cdot 24$ & 0.034 & $1 \cdot 0$ & -0.53 & $0 \cdot 48$ \\
\hline \multirow{2}{*}{ Coniferous forest } & $<2 \cdot 0$ & $4 \cdot 5$ & Ref & & $1 \cdot 4$ & Ref & \\
\hline & $\geqslant 2 \cdot 0$ & 1.6 & $-1 \cdot 20$ & 0.0007 & 1.9 & $0 \cdot 25$ & 0.56 \\
\hline \multirow[t]{2}{*}{ Orchards } & $<0 \cdot 2^{\mathrm{d}}$ & $3 \cdot 9$ & Ref & & $1 \cdot 4$ & Ref & \\
\hline & $\geqslant 0 \cdot 2$ & $4 \cdot 7$ & $0 \cdot 16$ & $0 \cdot 67$ & $2 \cdot 3$ & $0 \cdot 47$ & $0 \cdot 30$ \\
\hline \multirow{2}{*}{ Wooded wetlands } & $<2 \cdot 9$ & $3 \cdot 1$ & Ref & & $1 \cdot 3$ & Ref & \\
\hline & $\geqslant 2 \cdot 9$ & $5 \cdot 6$ & 0.43 & $0 \cdot 19$ & $1 \cdot 9$ & $0 \cdot 39$ & $0 \cdot 35$ \\
\hline \multirow[t]{2}{*}{ Non-wooded wetlands } & $<1 \cdot 3$ & $4 \cdot 1$ & Ref & & $1 \cdot 5$ & Ref & \\
\hline & $\geqslant 1 \cdot 3$ & $3 \cdot 8$ & $-0 \cdot 21$ & $0 \cdot 55$ & 1.9 & $0 \cdot 26$ & 0.57 \\
\hline \multirow[t]{2}{*}{ Disturbed lands } & $<0.5$ & $4 \cdot 1$ & Ref & & $1 \cdot 7$ & Ref & \\
\hline & $\geqslant 0 \cdot 5$ & $3 \cdot 9$ & $-0 \cdot 12$ & 0.71 & $1 \cdot 4$ & $-0 \cdot 18$ & 0.67 \\
\hline \multirow[t]{2}{*}{ Roads } & $<0 \cdot 3$ & $3 \cdot 1$ & Ref & & $1 \cdot 5$ & Ref & \\
\hline & $\geqslant 0.3$ & $5 \cdot 4$ & $0 \cdot 40$ & $0 \cdot 23$ & $1 \cdot 7$ & 0.09 & $0 \cdot 83$ \\
\hline
\end{tabular}

${ }^{a}$ Analysis conducted on the subset of dogs with complete exposure history data (1442 dogs).

${ }^{\mathrm{b}}$ For the 2011-2014 period.

${ }^{\mathrm{c}}$ Year 2013.

${ }^{\mathrm{d}}$ Third quartile as category cut-off, other cut-offs based on the median.

${ }^{\mathrm{e}}$ Reference category.

When based on the municipality as the epidemiological unit of interest, all NB models in humans had a poor fit according to the Deviance/DF statistics (all $\leqslant 0 \cdot 51$ ). Hence, the findings from these models are not presented. NB models based on counties had adequate fit statistics with Deviance/DF statistics ranging from 1.04 to 1.09 . The variable mixed forest was highly correlated with hardwood forest $(r=0 \cdot 72, P<$ $0 \cdot 001)$ and coniferous forest $(r=0.82, P<0 \cdot 001)$. The variable mixed forest was consequently excluded from regression analysis. The assumption of linearity in NB models was not met for all risk factors and these were categorized. The results of the univariate NB models based on counties are presented in Table 2 along with the outputs of univariate NB regression in dogs. Multivariate stepwise regression process resulted in keeping only the risk factor 'coniferous forest' (incidence risk ratio $=0 \cdot 30$ for areas with $\geqslant 2 \%$ of coniferous land cover compared with areas with $<2 \%$ of this land cover, $P=0.0007$ ) and discarding all other risk factors. Hence, no multivariate model was produced for NB models in humans. Overall, univariate models in humans mainly suggested a lower WNV incidence risk in forested areas. All remaining associations with other environmental factors were not statistically significant at $P<0.05$ on NB models.

Among the 1627 dogs tested, 28 dogs $(1.7 \%)$ were seropositive for WNV. Descriptive statistics for the individual characteristics of sampled dogs for which complete records were available $(N=1442)$ are presented in Table 3, and the geographical distribution of these dogs is presented in Figure 1e. On average, juvenile dogs were 6 months old, and adult dogs were $5 \cdot 1$ years old. On average, juvenile dogs were acquired by their owner 4.6 months before sampling, and adult dogs were acquired by their owners $4 \cdot 4$ years before sampling. Hence, most sampled dogs spent most of their life with their current owner.

As for human case data, NB models in dogs based on the municipality had poor fit statistics (all 
Table 3. Univariate associations between individual characteristics and seropositivity to WNV in 1442 dogs based on a logistic model

\begin{tabular}{|c|c|c|c|c|c|}
\hline & $N$ & $\%$ seropositive & $P$-value on type III test & $\beta$ & $P$-value \\
\hline \multicolumn{6}{|l|}{ Age } \\
\hline Juvenile & 665 & $0 \cdot 3$ & \multirow[t]{2}{*}{$0 \cdot 001$} & $\operatorname{Ref}^{\mathrm{a}}$ & \\
\hline Adult & 777 & $3 \cdot 2$ & & $2 \cdot 40$ & 0.001 \\
\hline \multicolumn{6}{|c|}{ Time spent outside daily } \\
\hline$<12 \mathrm{~h} /$ day & 1366 & $1 \cdot 2$ & \multirow[t]{3}{*}{$<0 \cdot 0001$} & Ref & \\
\hline 12-18 h/day & 25 & $8 \cdot 0$ & & $2 \cdot 06$ & 0.008 \\
\hline 18-24 h/day & 49 & $18 \cdot 4$ & & $3 \cdot 01$ & $<0.0001$ \\
\hline \multicolumn{6}{|l|}{ Date of sampling } \\
\hline Before July 15 & 945 & $1 \cdot 6$ & \multirow[t]{2}{*}{$0 \cdot 327$} & Ref & \\
\hline After July 15 & 519 & $2 \cdot 3$ & & $0 \cdot 38$ & $0 \cdot 327$ \\
\hline \multicolumn{6}{|l|}{ Breed } \\
\hline Small breed & 379 & $0 \cdot 26$ & \multirow[t]{2}{*}{0.029} & Ref & \\
\hline Large breed & 1080 & $2 \cdot 41$ & & $2 \cdot 23$ & $0 \cdot 029$ \\
\hline \multicolumn{6}{|l|}{ Sex } \\
\hline Male & 754 & 1.9 & \multirow[t]{2}{*}{$1 \cdot 00$} & Ref & \\
\hline Female & 700 & 1.9 & & $0 \cdot 00$ & $1 \cdot 000$ \\
\hline \multicolumn{6}{|l|}{ Hair length } \\
\hline Short & 979 & $1 \cdot 43$ & \multirow[t]{2}{*}{$0 \cdot 234$} & Ref & \\
\hline Long & 478 & $2 \cdot 30$ & & $-0 \cdot 48$ & $0 \cdot 234$ \\
\hline \multicolumn{6}{|l|}{ Use of insecticides } \\
\hline Never & 1166 & $1 \cdot 85$ & \multirow{3}{*}{$0 \cdot 464$} & Ref & \\
\hline Occasionally & 85 & $3 \cdot 4$ & & $0 \cdot 57$ & $0 \cdot 216$ \\
\hline All summer long & 169 & $1 \cdot 2$ & & $-0 \cdot 52$ & $0 \cdot 316$ \\
\hline \multicolumn{6}{|c|}{ Use of flea medication } \\
\hline Never & 564 & $1 \cdot 6$ & \multirow[t]{3}{*}{0.734} & Ref & \\
\hline Occasionally & 159 & $2 \cdot 5$ & & $0 \cdot 23$ & 0.591 \\
\hline All summer long & 696 & $2 \cdot 0$ & & $0 \cdot 46$ & $0 \cdot 454$ \\
\hline \multicolumn{6}{|c|}{ Use of mosquito repellents } \\
\hline Never & 1255 & $1 \cdot 8$ & \multirow[t]{3}{*}{$0 \cdot 784$} & Ref & \\
\hline Occasionally & 165 & $1 \cdot 8$ & & $-0 \cdot 008$ & 0.990 \\
\hline Every day & 27 & $3 \cdot 7$ & & $0 \cdot 72$ & 0.487 \\
\hline
\end{tabular}

${ }^{\mathrm{a}}$ Reference category.

Deviance/DF < 0.39). Consequently, the results of these models in dogs are not presented. The fit of the NB models based on the county was acceptable (Deviance/DF ranging from 0.80 to $0 \cdot 84$ ). The results of univariate NB models in dogs are presented in Table 2 in parallel with the NB model outputs in humans. None of the environmental risk factors had a statistically significant association with seropositivity in dogs at $P<0.05$ when modelled at the scale of the county. The only environmental risk factor having a $P<0.20$ in these models was 'agricultural lands' ( $P$ $=0 \cdot 19$ ).

Results of the univariate logistic models for the subset of 1442 dogs are presented in Tables 3 and 4. The linearity assumption was adequately met for all continuous predictors in logistic models. The results of the multivariate models in all dogs (1442) and in dogs never leaving their municipality (883) are presented in Table 5. These multivariate models identified agricultural lands as being favourable environments for infection in dogs after controlling for individual factors. The time spent outside daily and the age of the dog, when categorized as juveniles or adults, were also strongly and positively associated with seropositivity in this multivariate model. The model restricted to dogs never leaving their municipality showed a stronger association between agricultural lands and the odds of infection and had a slightly better fit than the one including all dogs. The HL statistics and the AUC were 0.60 and 0.85 , respectively, for the multivariate logistic model based on all 1442 dogs and 0.78 and $0 \cdot 87$, respectively, for the logistic model based on the 883 dogs never leaving their municipality suggesting a good fit and a good predictive ability for both models. 
Table 4. Univariate associations between residential surrounding factors $(2 \mathrm{~km}$ ) and seropositivity to $W N V$ in 1442 dogs based on a logistic model

\begin{tabular}{|c|c|c|c|c|}
\hline & $N$ & $\begin{array}{l}P \text {-value on } \\
\text { type III test }\end{array}$ & $\beta$ & $P$-value \\
\hline \multicolumn{5}{|c|}{ Pools of standing water on the property } \\
\hline None & 720 & $0 \cdot 21$ & Ref & \\
\hline Small pools & 482 & & $0 \cdot 08$ & $0 \cdot 857$ \\
\hline Large pools & 244 & & $0 \cdot 78$ & $0 \cdot 097$ \\
\hline \multicolumn{5}{|c|}{$\%$ of a buffer radius $2 \mathrm{~km}$ around the home covered by... } \\
\hline \multicolumn{3}{|c|}{ Agricultural lands } & $0 \cdot 20$ & $0 \cdot 001$ \\
\hline \multicolumn{3}{|c|}{ Developed lands } & $-0 \cdot 11$ & $0 \cdot 103$ \\
\hline \multicolumn{3}{|l|}{ Surface water } & $-0 \cdot 35$ & $0 \cdot 176$ \\
\hline \multicolumn{3}{|c|}{ Hardwood forest } & $0 \cdot 05$ & $0 \cdot 730$ \\
\hline \multicolumn{3}{|c|}{ Coniferous forest } & $-0 \cdot 42$ & $0 \cdot 652$ \\
\hline \multicolumn{3}{|l|}{ Orchards } & $-5 \cdot 59$ & $0 \cdot 627$ \\
\hline \multicolumn{3}{|c|}{ Wooded wetlands } & $0 \cdot 14$ & $0 \cdot 815$ \\
\hline \multicolumn{3}{|c|}{ Non-wooded wetlands } & $-0 \cdot 10$ & $0 \cdot 927$ \\
\hline \multicolumn{3}{|c|}{ Disturbed lands } & $-0 \cdot 81$ & $0 \cdot 528$ \\
\hline \multicolumn{3}{|c|}{ Roads/highways } & $0 \cdot 26$ & $0 \cdot 858$ \\
\hline
\end{tabular}

\section{DISCUSSION}

Since the introduction of WNV in North America in 1999, urban and suburban areas were identified as the main high-risk environments for WNV in northeastern USA [8,13-15]. These areas were associated with high populations of Culex pipiens, a vector that mainly breeds in artificial standing water pools and which has recently been incriminated as being responsible for more than $80 \%$ of WNV transmission in humans in north-eastern USA [6,11-15]. However, given the complexity of WNV epidemiology, questions remain on the full applicability of this knowledge for other geographical areas with different environmental conditions $[11,29,30]$.

Our findings suggest that WNV transmission conditions may be slightly different in southern Quebec than that previously reported for locations of northeastern USA [13-15,31]. For human case data, hardwood and coniferous forests were associated with a lower incidence risk for WNV in Quebec. This finding is consistent with a recent study from DeGroote et al., which also used county as the epidemiological unit and in which decreased risk in some forested areas of north-eastern USA was reported [32].

Regional incidence risks suggest that risk may be relatively low or intermediate in the highly urbanized area of Montreal city, while many suburban and agricultural areas appear as areas of higher risk. The potential impact of mosquito abatement interventions in developed areas must be considered in interpreting the relatively low incidence risk observed in the city of Montreal. Larvicides have been used in different locations of Quebec during the study period and may represent efficient mitigation measures against WNV according to some North American studies [4]. However, to our knowledge, mosquito abatement interventions directed against Culex species were relatively limited in Montreal in the 2007-2012 period. The most important outbreak of WNV in Quebec occurred in 2012. Following this outbreak, mosquito abatement interventions directed against WNV vectors were initiated in 2013 in selected areas of Montreal and Laval and in some locations in periphery of these two cities [33]. These interventions may have had an impact on the observed incidence risk in Montreal in the post-2012 period. Interestingly, although a significant proportion of the urban areas of Laval were also subjected to larvicide spreading against WNV vectors from 2013 [33], Laval had the highest observed regional incidence risk for the study period. The level of geographical aggregation used in this study does not allow to assess the relative impact of mosquito abatement interventions on risk.

In our NB models using human case data, agricultural land and developed land showed a tendency towards a higher risk, although they were not statistically significant. However, the fact that agricultural lands represent the main high-risk environment for WNV spillover to dogs supports the possibility of a significant WNV activity in these areas. Agricultural land was previously reported as a high-risk environment in western North America but not in the northeastern USA [34-36]. Higher risk in agricultural areas may be explained by the particular characteristics of the study area. A large part of southern Quebec comprises the lowlands of the Saint-Lawrence River Valley. Contrasting with the landscapes in other studies from north-eastern USA, the Saint-Lawrence River Valley is covered by large, flat croplands, which represent ideal breeding habitats for a number of potential WNV vectors such as Aedes vexans [8,37]. Although this last vector is thought to be less competent for WNV transmission than Cx. pipiens, it has been suggested that its high abundance in southern Quebec and its feeding preferences for mammals could effectively contribute to the phenomenon of WNV spillover to human populations [38]. On the other hand, it is plausible that $C x$. pipiens abundance may be higher both in agricultural and developed areas of southern Quebec and lower in hardwood or 
Table 5. Multivariate associations between individual and residential surrounding factors (2 km) and seropositivity to WNV in dogs based on a logistic model (final models)

\begin{tabular}{|c|c|c|c|c|c|c|}
\hline & \multicolumn{3}{|c|}{$1442 \operatorname{dogs}^{\mathrm{a}}$} & \multicolumn{3}{|c|}{ Subset of $883 \mathrm{dogs}^{\mathrm{b}}$} \\
\hline & OR & $95 \% \mathrm{CI}$ & $P$-value & OR & $95 \% \mathrm{CI}$ & $P$-value \\
\hline Percentage of agricultural lands (for a $10 \%$ increase) & $1 \cdot 15$ & $1 \cdot 01-1 \cdot 31$ & $0 \cdot 042$ & $1 \cdot 22$ & $1 \cdot 01-1 \cdot 46$ & $0 \cdot 036$ \\
\hline Time spent outside daily (for $1 \mathrm{~h}$ increase) & $1 \cdot 16$ & $1 \cdot 10-1 \cdot 21$ & $<0 \cdot 0001$ & $1 \cdot 14$ & $1 \cdot 07-1 \cdot 22$ & $<0.0001$ \\
\hline Age (adult $v s$. juvenile) & $10 \cdot 72$ & $2 \cdot 47-46 \cdot 5$ & $0 \cdot 002$ & $6 \cdot 18$ & $1 \cdot 31-29 \cdot 2$ & $0 \cdot 022$ \\
\hline
\end{tabular}

${ }^{\text {a }}$ Subset of dogs with complete exposure history data.

${ }^{\mathrm{b}}$ Subset of dogs that had never left their municipality of residence or Canada.

coniferous forests. Negative associations between forested land cover and Cx. pipiens population densities and positive associations between suburban and, to a lesser extent, agricultural land and $C x$. pipiens population densities have been reported in other locations of north-eastern USA [39]. Hence, higher risk in or nearby agricultural areas of Quebec may result from the additive effect of transmission by these two species. Further entomological field studies would be warranted to better understand the WNV transmission dynamics in these areas. Given that most suburban areas of southern Quebec are surrounded by agricultural lands and considering the relatively long flight range of some mosquitoes [27], the possibility of a significant risk of transmission in agricultural areas could eventually justify implementing WNV public health interventions, including surveillance, to a wider selection of high-risk geographical areas and including selected agricultural zones.

At the time this study was conducted, no individual data on cases of WNV infection in humans were available for research purposes. Hence, our analyses in humans were based on aggregated clinical data, which can lead to a number of limitations in a context of public health intervention planning. First, aggregated data are subjected to ecological bias [40]. Given that the distribution of risk factors among infected or uninfected subjects within each administrative area was unknown in the context of the current study, inferences from the NB models presented should be limited to these administrative areas. Consequently, the analysis based on aggregated data do not allow us to assess if risk inside administrative areas is really driven by environmental factors or by other factors, such as the behaviours of groups of individuals living in specific environments. In this context, it may be challenging to determine what would be the most appropriate preventive public health intervention between, for example, information campaigns aimed at changing behaviours or environmental interventions, such as the use of larvicides. Moreover, geographical aggregation of data according to administrative boundaries is also subjected to the modifiable areal unit problem, which can impact both the results of statistical models and the visual interpretation of risk maps [41]. As this level of geographical aggregation represents large geographic areas, it is probable that smaller scale environmental factors were not captured by NB models using human case data. Therefore, results based on human data must be interpreted with caution.

Jointly interpreting models for WNV infection in humans and dogs helped to better understand WNV transmission dynamics in the study area and analyses in dogs provided validation to some conclusions from descriptive statistics using human case data. First, for each dog, individual characteristics were available and could be controlled in the analysis to assess their potential confounding effect on environmental risk factors. For example, the time spent outside daily by the dogs was associated with risk, but dogs in rural areas usually spend more time each day outside, so this variable could potentially have had a confounding effect. However, by having data on both, we could determine that there was no significant confounding in terms of influencing coefficients in the multivariate model. Second, environmental data were extracted from small and well-localized areas centred on the exact house location, enabling capture of the potential effect of small environmental variations in the immediate surroundings of the dogs' location of residence. According to our data, $61 \%$ of sampled dogs had never left their municipality, thus limiting exposure misclassification related to usual human behaviours, such as moving for professional work or leisure, and thus possibly improving the capacity of the models to identify high-risk environments. The associations between environmental factors and risk were slightly 
stronger and the fit of the model slightly better in dogs that never left their municipality, which supports the potential benefits of limiting exposure measurement errors. Meanwhile, the concordance of the results between the two final models in dogs suggests that exposure measurement errors do not invalidate the results of analysis conducted on an unrestricted dog population. Although the percentage of seropositive dogs in our sample was low, it was substantially higher than the percentage of seropositive humans reported in the same area in $2014(0 \cdot 6 \%)$ [24]. Higher exposure of dogs to WNV compared with humans was reported in other studies in North America [20, 23].

We conclude that the findings from this study suggest that serological monitoring in dogs could provide more flexibility and precision than aggregated human case data for identifying WNV risk and risk factors, and may be robust enough to support public health decision making. Further research is warranted to quantify arboviral activity in less densely populated areas of the study region and to further analyze the benefits, limitations and applicability of using domestic animals as environmental indicators to supplement public health surveillance.

\section{ACKNOWLEDGEMENTS}

The authors thank all participating veterinary practitioners for providing data and serological samples for this study. The authors thank the Ministry of Health and Social Services of Quebec for providing the data on human WNV clinical cases and Ariane Massé from the Ministry of Forests, Fauna and Parks for providing data from the Ecoforest inventory system.

This study was funded by the Public Health Agency of Canada.

\section{DECLARATION OF INTEREST}

None.

\section{ETHICAL STANDARDS}

The dog serosurvey was approved by the Committee for Ethical Animal Use of the Université de Montréal (certificate \#13-Rech-1698). The authors assert that all procedures contributing to this work comply with the ethical standards of the relevant national and institutional guides on the care and use of animals in research.

\section{REFERENCES}

1. Komar N. West Nile virus: epidemiology and ecology in North America. Advances in Virus Research 2003; 61: 185-234.

2. Roehrig JT. West Nile virus in the United States - a historical perspective. Viruses 2013; 5: 3088-3108.

3. Centers for Disease Control and Prevention. West Nile virus disease cases and deaths reported to CDC by year and clinical presentation, 1999-2014 (http:// www.cdc.gov/westnile/resources/pdfs/data/1-wnv-diseasecases-by-year_1999-2014_06042015.pdf). Accessed 10 December 2015.

4. National Public Health Institute of Quebec. The risk of West Nile virus in Quebec and interventions prioritized in 2013 [in French] (http://www.inspq.qc.ca/pdf/ publications/1629_RisqueVNOQcIntervPrivil2013.pdf). Accessed 7 July 2015.

5. Gu W, et al. Fundamental issues in mosquito surveillance for arboviral transmission. Transactions of the Royal Society of Tropical Medicine and Hygiene 2008; 102: 817-822.

6. Kilpatrick AM, et al. West Nile virus risk assessment and the bridge vector paradigm. Emerging Infectious Diseases 2005; 11: 425-429.

7. Molaei G, et al. Host feeding patterns of Culex mosquitoes and West Nile virus transmission, northeastern United States. Emerging Infectious Diseases 2006; 12: 468-474.

8. Trawinski PR, Mackay DS. Identification of environmental covariates of West Nile virus vector mosquito population abundance. Vector Borne and Zoonotic Diseases 2010; 10: 515-526.

9. De Filette M, et al. Recent progress in West Nile virus diagnosis and vaccination. Veterinary Research 2012; 43: 16 .

10. Petersen LR, Brault AC, Nasci RS. West Nile virus: review of the literature. JAMA 2013; 310: 308-315.

11. Liu A, et al. Risk factors for human infection with West Nile Virus in Connecticut: a multi-year analysis. International Journal of Health Geographics 2009; 8: 67.

12. Liu H, Weng Q, Gaines D. Spatio-temporal analysis of the relationship between WNV dissemination and environmental variables in Indianapolis, USA. International Journal of Health Geographics 2008; 7: 66.

13. Rochlin I, et al. Predictive mapping of human risk for West Nile virus (WNV) based on environmental and socioeconomic factors. PLOS ONE 2011; 6: e23280.

14. Ruiz MO, et al. Environmental and social determinants of human risk during a West Nile virus outbreak in the greater Chicago area, 2002. International Journal of Health Geographics 2004; 3: 8.

15. Ruiz MO, et al. Association of West Nile virus illness and urban landscapes in Chicago and Detroit. International Journal of Health Geographics 2007; 6: 10.

16. DeGroote JP, et al. Landscape, demographic, entomological, and climatic associations with human disease incidence of West Nile virus in the state of Iowa, USA. International Journal of Health Geographics 2008; 7: 19 . 
17. Wimberly MC, et al. Ecological niche of the 2003 West Nile virus epidemic in the northern great plains of the United States. PLoS ONE 2008; 3: e3744.

18. Blackburn NK, et al. Susceptibility of dogs to West Nile virus: a survey and pathogenicity trial. Journal of Comparative Pathology 1989; 100: 59-66.

19. Kile JC, et al. Serologic survey of cats and dogs during an epidemic of West Nile virus infection in humans. Journal of the American Veterinary Medical Association 2005; 226: 1349-1353.

20. Komar N, Panella NA, Boyce E. Exposure of domestic mammals to West Nile virus during an outbreak of human encephalitis, New York city, 1999. Emerging Infectious Diseases 2001; 7: 736-738.

21. Ozkul A, et al. Serological evidence of West Nile Virus (WNV) in mammalian species in Turkey. Epidemiology and Infection 2006; 134: 826-829.

22. Phoutrides E, et al. The utility of animal surveillance in the detection of West Nile virus activity in Puerto Rico, 2007. Vector Borne and Zoonotic Diseases 2011; 11: 447-450.

23. Resnick MP, et al. Juvenile dogs as potential sentinels for West Nile virus surveillance. Zoonoses and Public Health 2008; 55: 443-447.

24. Rocheleau JP, Environmental characteristics of risk of exposure to arboviruses in Quebec. Thesis, Université de Montréal, 2016, $284 \mathrm{p}$.

25. Calisher CH. Medically important arboviruses of the United States and Canada. Clinical Microbiology Reviews 1994; 7: 89-116.

26. Howard JJ, White DJ, Muller SL. Mark-recapture studies on the Culiseta (Diptera, Culicidae) vectors of eastern equine encephalitis-virus. Journal of Medical Entomology 1989; 26: 190-199.

27. Service MW. Mosquito (Diptera : Culicidae) dispersal The long and short of it. Journal of Medical Entomology 1997; 34: 579-588.

28. Dohoo IR, Martin SW, Stryhn H. Veterinary Epidemiologic Research, 2nd edn. Charlottetown, P.E. I.: VER, Inc., 2009, pp. 366-461.

29. Hongoh V, et al. A review of environmental determinants and risk factors for avian-associated mosquito arboviruses in Canada. Biodiversity 2009; 10: 9.

30. Bellini R, Zeller H, Van Bortel W. A review of the vector management methods to prevent and control outbreaks of West Nile virus infection and the challenge for Europe. Parasites \& Vectors 2014; 7: 323.
31. Brownstein JS, et al. Spatial analysis of West Nile virus: rapid risk assessment of an introduced vector-borne zoonosis. Vector Borne and Zoonotic Diseases 2002; 2: 157-164.

32. DeGroote JP, Sugumaran R, Ecker M. Landscape, demographic and climatic associations with human West Nile virus occurrence regionally in 2012 in the United States of America. Geospatial Health 2014; 9: 153-168.

33. Ministry of Health and Social Services of Quebec. Government intervention plan 2013-2015 for the protection of the population against the West Nile virus [in French] (http://publications.msss.gouv.qc.ca/msss/ fichiers/2014/14-211-01W.pdf). Accessed 6 June 2017.

34. Fauver JR, et al. Temporal and spatial variability of entomological risk indices for West Nile virus infection in Northern Colorado: 2006-2013. Journal of Medical Entomology 2016; 53: 425-434.

35. Tevie J, Bohara A, Valdez RB. Examination of the geographical variation in human West Nile virus: a spatial filtering approach. Epidemiology and Infection 2014; 142: 2522-2529.

36. Randall NJ, Blitvich BJ, Blanchong JA. Association between agricultural land use and West Nile virus antibody prevalence in Iowa birds. Journal of Wildlife Diseases 2013; 49: 869-878.

37. Maire A, Aubin A. Mosquitoes from Quebec (Diptera: Culicidae) ecological synthesis study [in French]. Memoirs of the Entomological Society of Quebec 1980; 6: 21-22.

38. National public Health Institute of Quebec. Strategic impact assessment of the governmental plan for protection of public health against West Nile virus - Sector report 1 - Issue of West Nile virus [in French] (http:// www.inspq.qc.ca/pdf/publications/ 447-VNO-RapportSectoriel1_Programme.pdf). Accessed 7 April 2015.

39. Diuk-Wasser MA, et al. Modeling the spatial distribution of mosquito vectors for West Nile virus in Connecticut, USA. Vector Borne and Zoonotic Diseases 2006; 6: 283-295.

40. Rothman KJ, Greenland S, Lash TL. Modern Epidemiology, 3rd edn. Philadelphia; London: Lippincott Williams \& Wilkins, 2008, p. 519.

41. Waller LA, Gotway CA. Applied Spatial Statistics for Public Health Data. Hoboken, N.J.: John Wiley \& Sons, 2004, pp. 104-108. 